\title{
Acute Pulmonary Embolism after catheter cryoballon ablation of atrial fibrillation
}

Bara Al-Qudah ${ }^{1}$, Mohammed Al-Attiya ${ }^{1}$, Mohamed Shariff ${ }^{1}$, and Mohammed Alzyod ${ }^{1}$

${ }^{1}$ Hamad Medical Corporation

October 19, 2021

\begin{abstract}
Periprocedural venous thromboembolisms (VTEs) area rare occurrence but a critical complication after catheter ablation of atrial fibrillation $(\mathrm{AF})$.here we report a 39 year old gentleman treated for paroxysmal atrial fibrillation with catheter cryoablation ,while was compliant to anticoagulation with DOAC dabigatran . one week later he developed acute PE
\end{abstract}

\section{Hosted file}

editedprimer2-converted.pdf available at https://authorea.com/users/441810/articles/542259acute-pulmonary-embolism-after-catheter-cryoballon-ablation-of-atrial-fibrillation

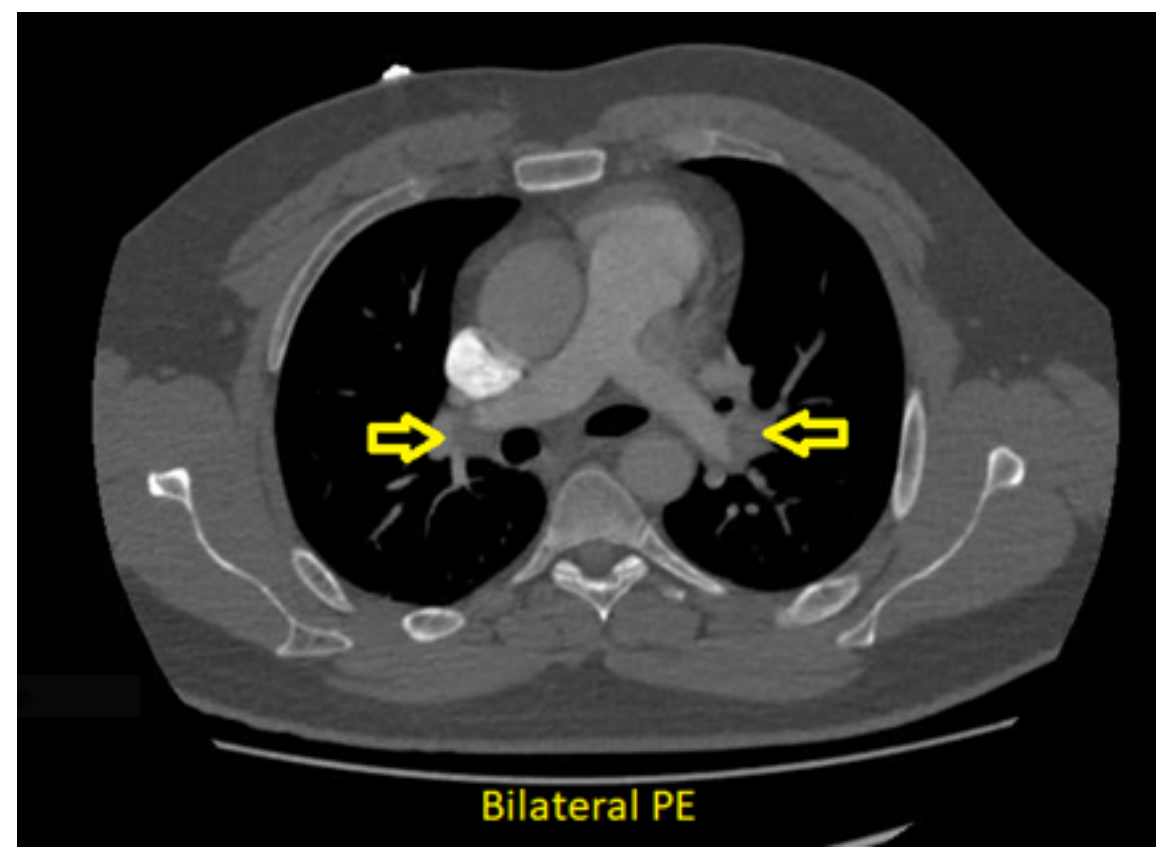




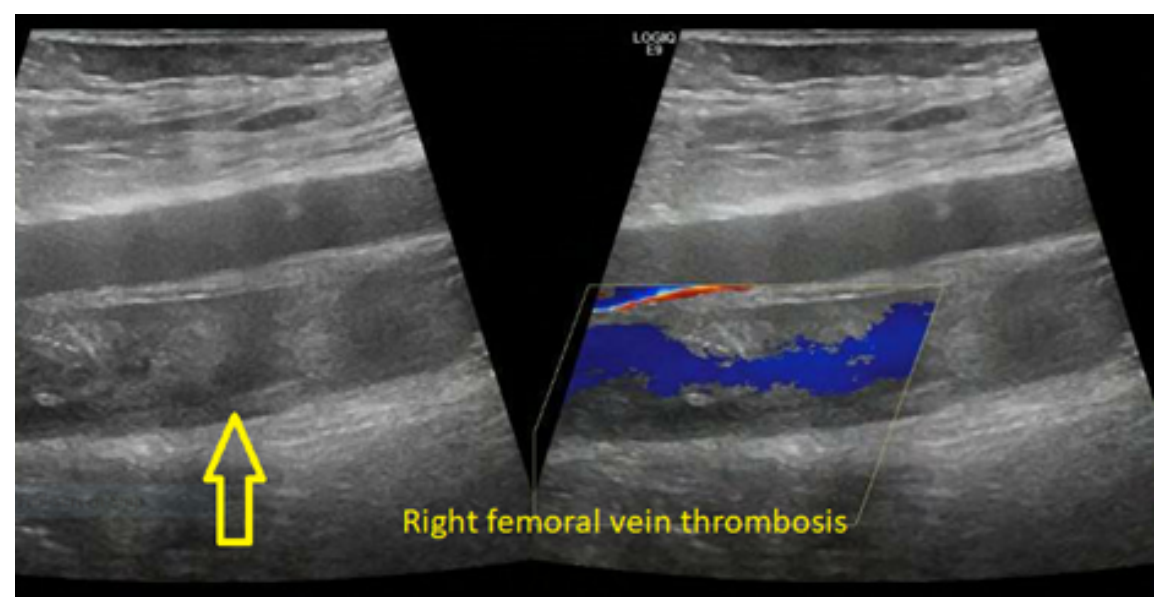

